\title{
A Research on the Influence of Contemporary Popular Music upon Youths' Self-identity
}

\author{
Wang Jing* \\ College of Chinese Language and Culture, Jinan University, Guangzhou, China \\ Corresponding Author: Wang Jing, E-mail: wangjing@hwy.jnu.edu.cn
}

\section{ARTICLE INFO}

Article history

Received: June 01, 2017

Accepted: September 15, 2017

Published: October 31, 2017

Volume: 8 Issue: 5

Advance access: October 2017

Conflicts of interest: None

Funding: None

Key words:

Emotion,

Self-identity,

"Emotion-identity"

\begin{abstract}
"Emotion" is a key to exploring the relationship between contemporary popular music and youths. In reality, youths exercise the identity construction centering on self-identity by the unconscious use of ritualization towards popular music (cultures). The article analyzes the conversion in identity construction of youths in the course of popular music appreciation in the new era, and summarizes the identity construction of "private - individual", "public - individual", "selfdivision" and "reflexive". The study on varieties of identity types strengthens our belief that "emotion-identity" is a down-to-earth approach to research Chinese youth group of popular music appreciators.
\end{abstract}

\section{INTRODUCTION}

Popular music is mainly targeting youngsters, no matter at home or abroad. From those born in 1960s and 1970s who secretly listened to Teresa Teng' songs in bed to today's worshipers of J-pop and K-pop as well as Western music, generations of youngsters grow up in popular music. Music is at all times connected with emotions, which is so prominent a feature of China's popular music that it is safe to say that without the desire to set things right and outburst emotions once suppressed for 10 years by the Cultural Revolution, there would be no psychological basis and mass support for popular music revival in China. For over 30 years, contemporary popular music, which keeps chanting about feelings, has been expressing various emotions of people and fitting into or participating in the emotion construction of populace (especially youths) in different times and of different social status.

Connected indirectly with perception and ideology, "emotion" is a must-have research conception in studying the relationship between contemporary popular music and youths. Nevertheless, a puzzling but interesting phenomenon disclosed in such investigations is that: the vast majority of youths interviewed said that not much of influence is made by popular music on their thoughts and emotions when asked in an attempt to identify the effect on them; they disagreed with this view and said it has influences more or less when asked if it can be said that popular music doesn't really have influences on youths - which once have made us very confusing. Not until we rethink the researches on western popular music culture and put the development of contemporary Chinese popular music into a broader historical perspective, did we realize that the contradictory perception of youths regarding this issue actually has something to do with their unconscious use of ritualization towards popular cultures characterized by popular music. The reason of referring to the exercise of popular of culture by them as "ritualization" is not only that they accept and collect the symbolic systems given by popular cultures and process and use them at random, but also that they make symbolic systems stand out by giving them a sense of "significance" and extensiveness, making it a complex of "reality/imagination" just as "rituals" suggested by sociology and anthropology. By ritualization, youths may not necessarily establish the emotional bond with the contexts of some popular music, but they exercise the identity construction centering on self-identity.

\section{DEFINITION OF "SELF-IDENTITY"}

"Identity" is a complex concept with various significations as "unity", "personal identity", "identification" and more, concerning many issues in fields like philosophy, logic, sociology, politics and psychology. Zhang Jing, a Chinese expert specializing in identity research, gives a widely-accepted definition of "identity" 
Identity is the position of social beings in society, the core of which includes specific rights, obligations, responsibilities, loyalty targets, identifications and codes of conduct and also covers the justifications of these rights, responsibilities and loyalty. If such justifications changed, so would the loyalty and the sense of belonging of social beings, with some rights and responsibilities excluded from the existing conduct examples and people beginning to try new rules of action. All of these are implied in the recognition of social identity and accepted, acknowledged, followed and expected by social beings (Zhang, 2006).

This shows that "identity" is social beings" "position" in society but its definition is decided by the correlation and changes of the complicated social relations and the reactions towards them from human "the subject" as well. Scholar Tao Jiajun simplifies the issue by categorizing "identity" into four types - "individual identity", "collective identity", "self identity" and "social identity": "Firstly, the identific tion between individuals and specific cultures is individual identity. From a cultural perspective, the power operation of cultural organizations, during the process of identific tion makes individuals actively or passively participate in cultural practices so as to realize their identities. Secondly, collective identity means cultural subjects making a choice between two different cultural groups or sub-groups. Being influenced by different cultures, the cultural subjects need to regard one culture as their collective identity and another culture as "the other". Thirdly, self-identity emphasizing the psychological and physical experience of the self which serves as the core is the object of interest for the philosophy of Enlightenment, phenomenology and Existentialism. Fourthly, social identity which highlights the social attributes of human beings, is the research object for sociology, cultural anthropology. Individual identity and collective identity can be included into social identity, but do not reject the psychological and physical experience of the self"(TaoJiajun, 2004). In fact, the key issue of identity can be transformed into clearer but common questions - "Who am I? Where am I from? Where do I go?" However, the quests and answers to the problem are affected by the times they live in.

Throughout the process of identity construction in modern times, the identity of social beings can be roughly described as a process from "being endowed" to "shaping". Generally, the identity of social beings in premodern times is "endowed". For example, people were separated into "noblemen" and "peasants", or "superiors and "inferiors". Such identity was destined by the bloodline once they were born in and could hardly be transformed. Marxism acutely discovered that the distinction of social identity was decided by the production system of feudalism, which was changed to the need for capitalistic development of production system, resulting in an alternative identity recognition when people gradually broke free from an "endowed" premodern identity and came into, fluidity in identity construction. As in "Critique of Hegel's 'Philosophy of Right", Marx pointed out that, hierarchies in premodern times are made according to the need and the rule of politics, "it makes him an animal whose being coincides immediately with its determinate character"(Marx, 1956). Ever since modern times, people had been free from feudalistic personal relations and social hierarchies became "a division of the masses whose development is unstable and whose very structure is arbitrary and in no sense an organization"(Marx, 1956). However, this kind of "liberation" is in fact a "freedom" to sell their own labor for adjusting themselves to the social relations reform of capitalistic production mode. In modern society, which class one belongs to is dependent on opportunities or the kind of work engaged. The criterion of classification is "money and upbringing". In other words, what decides class is not regulated by law but according to the principle of "consumption and consumption ability" and eventually, the reality finds that it is in accordance with property relations and production relations that the class division is made among social beings (Zhou, 2011). In different stages of modern society, changes may have been found in identity construction methods, but never on the general principle.

With the transformation of identity construction deepening, cultural symbols began to take effect. Bourgeoisie gained dominance on the one hand through social enlightenment by wider promotion literature/arts criticism in the public sphere and, on the other, through their acquisition of patronage of literature/arts from the hands of feudal aristocracy so as to build and maintain their own cultural hegemony (See Jurgen Habermas's The Structural Transformation of the Public Sphere). After World War II, a generation of youth utilized popular cultures as their voice against the capitalism-dominated social mainstream cultures, which is fully revealed in Andy Bennett's Cultures of Popular Music. Here's an example:

When Rock Around the Clock was first screened in Britain, shortly after its release in 1956, it resulted in a string of minor disturbances. Cinema seats were torn out and in several major cities youths were arrested and later fined for aggressive or insulting behaviors as they left cinemas...... Across Europe, reactions to Rock Around the Clock were even more extreme than in Britain. In Hamburg of the West German cars were overturned and shops fronts and streets signs vandalized by young people as police used water cannons in an attempt to quell the unrest...... Similarly, in the Netherlands, where the film was banned in several major cities, "young people took to the streets to demonstrate for their right to see the film"...... Disturbances were also reported in Toronto, Sydney and in Auckland, New Zealand......(Bennett, 2012).

Rock ' $n$ ' roll is no exception; things turned out the same with heavy metal and punk. However, Bennett holds that the significance of youths' exploiting popular cultures like popular music is not so much of resistance as of an attempt to use these cultural symbols presenting a self-image shaping different from the previous generation. He believes that "'post-war' consumerism offered young people the opportunity to break away from their traditional class-based identity [and adopt] new, self-constructed forms of identity" (Bennett, 2012). 


\section{THE CONVERSION OF IDENTITY CONSTRUCTION IN THE NEW ERA}

The contemporary revival of popular music in China suggested that, similarly, identity construction patterns have changed. Before the new epoch, almost all the social beings were unexceptionally endowed with such identities as "proletarian" and "the revolutionary", but this "unity" in the construction showed disintegration after ideological emancipation and the reform and opening up policy in effect. After trauma of those ten years was consoled, a generation of elite young writers with enlightenment aspiration cried out "I don't believe" via misty poetry while the call of contemporary popular music (including those songs associated genealogically with the music) contains three ingredients:

One is the imitators and followers of Teresa Teng. Teresa's softness and sweetness in ballad performance satisfied mainlanders' (especially youths') long craving for comfort and aesthetics, despite the fact that her singing was no more trendy in Hong Kong and Taiwan in late 1970s and early 1980s. Therefore, one scholar wrote that "late 1970s and early 1980 s witnessed the reappearance of popular music, starting quietly with cassette types entering mainland from $\mathrm{HK}$ and Taiwan, among which the most representative was Teresa Teng's. Her singing was of such tenderness and warmth in her lyrics so clear with sincerity and her melody so brisk with the live band accompaniment. For the masses woke up from the nightmarish Cultural Revolution, youths were bored with those "high-pitched, rigid, fast-tempo" model music allowed by the government in particular, this light and lyrical music matched perfectly the urgent need for aesthetics" (Ju,1993).

It is the irreproducible demand for emotion conditioned by history that determined Teresa Teng's status and popularity in Chinese mainland. Due to the lack of necessary copyright awareness, in mainland's popular music in progress appeared a group of singers proclaiming themselves or were proclaimed to be "Teresa Teng II"(today's so-called "divas" - Faye Wong, Tian Zhen, Na Ying, etc.,-were among the list). The numerous cover versions make it hard to distinguish their own signature songs from their imitations of Teresa Teng. The conversion in aesthetics and emotion expression implied a change to identity awareness when "private-individual" identity built from the expression of ordinary emotions replaced the previous social identity of "unity" and "revolution-class" that was softly killed or deconstructed by such music.

The second one is freshness and freedom from vulgarity reflected in the process starting from making mere cover versions of Taiwan campus folk songs to composing independently Let the World Full of Love (Rang Shijie Chongman Ai). As we have mentioned elsewhere, although Taiwan campus folk songs resist to be a part of production system of cultural industry, they are an important source for Chinese contemporary music in terms of music contents. In other words, Taiwan campus folk songs significantly influenced Chinese contemporary music in the wake of commercialized pop music of HK and Taiwan such as Teresa Teng's songs. The effect was traceable not only in "folk fever" in 1994 but also from many songs featured as "intermediate tone" (a term, coined by Li Wan, famous music critic of China, to refer to music that connects subtly with ideology but satisfies national need for aesthetics and emotion expression) as early as in 1980s. Different from those Teresa-Teng-styled romance-themed songs, folk-featured songs regarded individual expression as inexorable "human nature", and a manifestation of humanistic feelings and lofty ideals, whose best representation was the song Let the World Full of Love, a gift to the International Year of Peace as its US counterpart We are the World and Taiwan's A Better Tomorrow (Mingtian Hui Genghao). The writing of such songs was of obvious public welfare, therefore, "I" the subject and "you" the object in it did not equal to those "you and I" in lovethemed popular songs. When Teresa Teng and her imitators sang The Moon Represents My Heart (Yueliang Daibiao Wode Xin), the "I" however affectionate in the song is just the subject of "private - individual", only a personal identity with awareness for a "smaller self". In contrast, as singers affected by Taiwan campus folk like Guo Feng chant "no matter whether you and I once knew each other" (lyrics from Let the World Full of Love), the "I" stands at the position of subject symbolizing humanistic and public awareness, or to say, the identity of "public - individual" and an awareness for a "bigger self". Developing all the way to Northwestern style (a popular music style rooted in the Northwestern regional culture of China), this "bigger self" survived and even grew into other fields. Anyhow, it was no longer the collective "revolution - class" identity as before the new era.

The third one is 1980s' rock ' $n$ ' roll represented by "With Nothing at all (Yiwu Suoyou)". Through the song and its writer/performer Cui Jian, some saw "the perfect combination of individual heroism and the collectivism for revolution"(Zhang,1999), and some noticed the destruction of "revolution" myths and the subsequent entanglement between the ecstasy and despair for sacrilege and the yearning and bewilderment for youth. There are people who observed a novel ideal of personality — “a real man doesn't want or need others to prepare everything for him and thus he is free to go for what he pursues"(Zhou, 2002). The interpretations mentioned above help us discern what With Nothing at all depicts is a psychological emptiness arising in the social transitional period between the lingering old ideology and the sprouting new one. As a result, the vacuum, waiting for new values and stances to fill in, became a feeling of loss in people, whose desolation and freedom intertwined. On the other hand, Cui Jian's rock music shows a dilemma of values: ideologically it fights against traditional values of "revolution" but symbolically it is reluctant to part the classic style of "revolution". As is Cui himself said, he was still "Balls under the Red Flag (Hongqi Xiade Dan, an album title and song title of his)" and found "no destination and no stronghold" although he had to launch "A New Long March" and that he instead carried the ideological birthmark of the old era. Therefore, we find unexpectedly that, in the field of rock ' $n$ ' roll, the most rebellious form of popular music, Cui Jian inherits the tradition in a radical way, which suggests that under the surface of With Nothing at all is a sense of confusion and loss of identity so much that some took it for an endorse- 
ment of emerging private business, as the unprecedented social group generated by the just-launched social transition, couldn't find their place politically or culturally. However, the "I" in the love-themed narration of "With Nothing at All" may have bid farewell to "revolution-class" identity, but it was not falling for the "private-individual" identity as in Teresa Teng's songs. Meanwhile, in terms of self awareness, that "I" in Balls under the Red Flag was one step away from being the "public - individual" identity in Let the World Full of Love. In a way, the critical thoughts in Cui Jian's rock is, above all, a profound and powerful self reflection, but deep beneath the "I", an awareness of self division coexists and rejects both the identity of "private-individual" and"public-individual".

No matter which identity, they all distinctly distance themselves from the former identity. With or without a clear consciousness about its meaning as an identity, pop music shows apparent difference in style from the previous one, providing symbolic resources and capital for youths in the new era to manifest their cultural identities. In other words, listeners of a certain kind of popular music don't necessarily mean their acceptance of the content it conveys but a feeling that they are free from the restraints of predecessors' taste and free to redefine what fashion is; even, they are proud to be a unique being. Due to the existence of those already mentioned identity structures, we cannot deny the factor of resistance and rebellion in their popular music appreciation (e.g. rock 'n' roll), but a deeper analysis will find that such fondness is based more on their emotional need and aesthetic taste. Since 1990s, this implication has grown even more evident, or we may say that popular music expresses more of the "private-individual" identity. After the fleeting climax in 1993, China's rock 'n' roll soon became marginalized with shrinking fans community. The fact that it even went underground was worsened with more critics than lovers of rock ' $n$ ' roll among youngsters. Still in this year when rockers like The Tang Dynasty Band and Zhang Chu attracted great attention, the biggest commercial success was undeniably Black Panther Band, whose lead vocal Dou Wei cried "I have no place to hide" (lyrics of the song Wudi Zirong, translated to English as No Place to Hide). Compared with Cui Jian's "I have nothing at all", this line renders a marked distinction in theme and identity. When Dou Wei continued "Don't talk too much when you know what you and I are looking for", the "I" is of more unrestrained wildness than the affectionate self in Teresa Teng's love songs, however, the two are actually the same with regard to the essence of identity. Not to mention other popular love songs represented by Mao Ning (Chinese male singer) and Yang Yuying (Chinese female singer) that were wearing masks either of quasi-urban style or pseudo country music style or any other style - they as well recognize the "private-individual" identity.

\section{THE IDENTITY CONSTRUCTION OF REFLEXIVE IN NETWORK ERA}

With the continuing adjustment in the structure of worldwide social economy and that of culture as well as the impact of new media like Internet, a new change has occurred in identity construction both at home and abroad. In reference to a concept suggested by theorists Anthony Giddens and Ulrich Beck, the change can be described as reflexive identity construction. Since the focus of the two theorists is the social analysis of modernity, here we only have a brief discussion in terms of identity issues with no inclination to quote their specific presentation in works like Reflexive Modernization. It is widely believed that refle ive has double meaning: self-refutation and reflection and Ulrich Beck stresses the former and Anthony Giddens the latter. When it comes to the identity issue, self-refutation makes us realize the deconstruction of the relatively steady identity formed in the single or organized modernity process (or "early modernity" suggested by some other scholars) dominated by enlightenment and rationality, or in other words, the "self" that has developed in line with the modernity logic, now transforms strangely into "self-resolution". However, it doesn't mean that self turns to nihilism completely, as self-reflection shows that, the formation of "cosmopolitan society" and "risk society" (or "late modernity") makes the world of more variety, individuation and openness, in which the identity of each and every one, though undoubtedly increasingly blurred, is provided with more possibilities; that is to say, greater uncertainty and flexibil ty appear in identity construction, as is said by Paul Sweetman "individuals must now choose their identities from the range of possibilities on offer. Self-identity has become 'a relatively organized endeavor '....... and 'individuals must [now] produce, stage and cobble together their biographies themselves'......'(Sweetman, 2012). In reflexive identity construction, all kinds of fashions, popular cultures or "subcultures" become important resources producing flowin and obscure games of style.

The identity choice by popular music fans can be regarded as the result of reflexive identity construction, since individuals can choose according to their interest from a mass of possibilities provided by society in a more private way of consumption and implement the cultural practice of "producing, staging and cobbling together", which fully embodies the characteristics of reflexive identity constructiondiversity, fragmentation and fluidit, thus the construction of an identity narration depending on individual interest. It is in this fan culture practice that we find the echo of Paul Sweetman's "a resurgence of sensuality and the emergence of affectuality-based forms of sociality" This is what Michel Maffesoli and Zygmunt Bauman called "neo-tribal" sociality (Sweetman, 2012). Accordingly, we can say that, at the meantime of reflexive identity construction, the emergence of popular music fan groups proclaims the existence of such a "neo-tribal" collective identity based on interest and emotion.

Andy Bennett applied Maffesoli's "neo-tribal" to the research of contemporary dance music:

Underpinning Maffesoli's concept of tribes is a concern to illustrate the increasingly fluid and unstable nature of social relations in contemporary society. According to Maffesoli (1996: 98), the tribe is 'without the rigidity of the forms 
of organization with which we are familiar; it refers more to a certain ambience, a state of mind, and is preferably to be expressed through lifestyles that favor appearance and form'. Two readings of Maffesoli's work provide further clarification of the point. Hetherington (1992: 93) suggests that tribalization involves 'the deregulation through modernization and individualization of the modern forms of solidarity and identity based on class occupation, locality and gender... and the recomposition into "tribal" identities and forms of sociation. Similarly, Shields (1992) suggests that tribal identities serves to illustrate the temporal nature of collective identities in modern consumer society as individuals continually move between different sites of collective expression and 'reconstruct' themselves accordingly. (Bennett, 2012).

Drawing from their theoretical concepts, Andy Bennett holds that the dance club provides a vivid example of "neo-tribal" associations: "Providing a space for expressions of 'togethernss' based on articulations of fun, relaxation, and pleasure, the club setting can be seen as one of many forms of temporal engagement through which such neo-tribal associations are formed. Indeed, in many of the larger clubs which feature urban dance music nights, the desire of clubber to choose from and engage with a variety of different crowds has been further enhanced through the use of different rooms or floors as a means of staging parallel dance events with club-goers free to move between these events as they please. Consequently, the clubbing experience is becoming increasingly a matter of individual choice, the type of music heard and the setting in which it is heard and danced to being very much the decision of the individual consumer.'(Bennett, 2012).

Perhaps, China isn't so developed in dance club setting as in western countries, but popular music appreciators can experience relatively the same in new media like the Internet. Assisted by the interactivity of new media, appreciators can, according to their own interest, in this wide cyber-space form various tribe-like groups, in which the most senior and passionate fans become leaders in initiating discussions and other activities while common fans use the platform to communicate with each other. Though they never meet, they come together out of similar hobby with the help of new media and form "imaginary communities" identifying with each other. However, these "communities" normally have no virtual binding effect on members who can quit easily if they have lost the interest or join new "tribes" and get new identity if the interest changes. This way of sociation is almost the same as that in a western dance club setting observed by Andy Bennett, revealing that the decisive base for "neo-tribal" is always interest and emotion whether at home or abroad. That's why Paul Sweetman says "Neo-tribalism can ultimately be seen as an aesthetic form of sociality, favoring 'appearance and form' (Maffesoli, 1996, p.98) - as an expression of shared feelings and experiences......In this context, particular places, things, or behaviors can assume iconic significance, acting as badges of recognition, confi mation of the group's existence, and strengthening communal ties"(Bennett, 2012).

\section{THE RESEARCH PATH OF "EMOTION- IDENTITY"}

To make an overview of identity construction in popular music appreciation, we see three types of identity: firstl , "power-identity" that highlights the political significanc and ideological content of identity construction, represented by rock 'n' roll appreciators; secondly, "emotion-identity" targeting at fulfilling individual emotional needs or getting connected with certain structured feelings, such as listeners of love songs for post-traumatic cure and listeners of self-help songs; thirdly, "taste_-identity" based on temporary interest or music styles, characterized by fans of R\&B music, western popular music, Korean popular music, etc. As for Chinese appreciators of popular music, although the "power-identity" one is so obvious that the other two types are correlated internally with it, still the other two are dominant in numbers. Besides, "taste-identity" will naturally lead to emotions as "like" and "dislike". In this sense, it is also included in "emotion-identity", the concept of which is proposed by us to make it an umbrella term to cover the analysis of emotional content and taste types of popular music in an attempt to explore the structure of feeling and identity issue within. In other words, we want to demonstrate "emotion-identity" as a more down-to-earth research approach to study Chinese youth group of popular music appreciators.

\section{ACKNOWLEDGMENT}

The article is a periodic achievement of Youth Project of Humanities and Social Science Research supported by Ministry of Education, entitled "A Research on the Influence of Contemporary Popular Music on Youths' Self-identity" (12YJCZH317).

\section{REFERENCES}

Bennett, A. (2012). Cultures of Popular Music. Trans. Qu Chuangliang.p.15. Beijing: Beijing University Press.

Bennett, A. (2012) Cultures of Popular Music. Trans. Qu Chuangliang. p.162. Beijing: Beijing University Press. Bennett, Andy. (2012). Cultures of Popular Music. Trans. Qu Chuangliang. p.163. Beijing: Beijing University Press.

Ju, Xi. (1993). 20 Century's Chinese Music.p.124 Qingdao: Qingdao Press.

Marx, K. (1956).“Critique of Hegel's 'Philosophy of Right'”, in The complete works of Marx and Engels, Vol.1.p.346 Beijing: People's Publishing House.

Sweetman, P. (2012). "Tourist and Travelers? 'Subcultures', Reflexive Identities and Neo-Tribal Sociality". Ed. Andy Bennett et al. After Subculture: Critical Studies in Contemporary Youth Culture.pp. 97-98. Beijing: China Youth Press.

Tao, J. (2004). An Introduction to Identity.Foreign Literature. No.2

Zhang, J. (2006). "Identity: the social allocation and identi- 
fication of civil rights". Studies on Identity. Ed. Zhang Jing. Vol.4.pp. 4-9.Shanghai: Shanghai People's Publishing House.

Zhang, X. (1999). "Cui Jian: the Great Bastard of Our Times", Southern Metropolis Daily. Sep. $14^{\text {th }}$.
Zhou, G. (2002). An Jing. pp. 130-131.Taiyuan: Beiyue Literature and Arts Press.

Zhou, X. (2011). The Displacement of Critique: Gramsci and the Turn of Cultural Studies.p15. Beijing: China Social Sciences Press. 